\title{
PENINGKATAN LOYALITAS PENUMPANG MELALUI STANDAR PELAYANAN MINIMUM PADA KERETA API PANGRANGO JALUR BOGOR -SUKABUMI
}

\author{
THE INCREASE OF PASSENGER LOYALTY TROUGT MINIMUM SERVICE \\ STANDARD ON PANGRANGO RAILWAY OF BOGOR -SUKABUMI LINE
}

\author{
Siti Maelani ${ }^{1)}$; Endang Silaningsih ${ }^{2)}$ \\ Program Management Studies Faculty of Economics, University of Djuanda Bogor \\ Email :_ ${ }^{1)}$ sitimaelani@yahoo.com; silaningsih toegiono@gmail.com ${ }^{2)}$
}

\begin{abstract}
This study aims to determine the effect of minimum service standards (MSS) on the Pangrango train at Bogor Paledang station on passenger loyalty. Data collection through interviews and questionnaires distributed to 100 respondents. After valid and reliable data, the test used is multiple linear regression to measure the effect of MSS on station and MSS in travel on passenger loyalty. The test used is F-test and t-test to determined the effect of MSS on station and MSS in Travel on passenger loyalty. The results of this study are all valid and reliable. Indicators simultaneously MSS on Station and MSS in Travel have a positive and significant impact on passenger loyalty $(Y)$. Furthermore, partially all indicators have a positive and significant impact on passenger loyalty. The variable that has a bigger influence is MSS in Travel.
\end{abstract}

Keywords: Minimum Service Standards (MSS) On Stations, Minimum Service Standards (MSS) In Travel and Passenger Loyalty

\begin{abstract}
ABSTRAK
Penelitian ini bertujuan untuk mengetahui pengaruh standar pelayanan minimum (SPM) terhadap loyalitas penumpang. Pengumpulan data dilakukan dengan wawancara dan penyebaran kuesioner kepada 100 responden. Setelah data dinyatakan valid dan reliabel, digunakan uji regresi linear berganda untuk mengukur pengaruh SPM pada stasiun dan SPM dalam perjalanan terhadap loyalitas penumpang. Selanjutnya dilakukan uji F dan uji-t untuk mengetahui pengaruh SPM pada stasiun dan SPM dalam perjalanan terhadap loyalitas penumpang. Hasil dari semua indikator valid dan reliable. Secara simultan SPM pada Stasiun dan SPM dalam Perjalanan berpengaruh positif dan signifikan terhadap loyalitas penumpang. Selanjutnya, secara parsial semua indikator berpengaruh positif dan signifikan terhadap loyalitas penumpang. Variabel yang memiliki pengaruh lebih besar yaitu SPM dalam perjalanan.
\end{abstract}

Kata Kunci : Standar Pelayanan Minimum pada Stasiun, Standar Pelayanan Minimum dalam Perjalanan dan Loyalitas Penumpang 


\section{PENDAHULUAN}

Transportasi merupakan kebutuhan sarana yang paling primer untuk kelangsungan berbagai kegiatan atau aktivitas. Transportasi memiliki arti sebagai pergeseran barang atau manusia dari tempat asal menuju tempat tujuan. Proses pengangkutan ialah aktivitas dari tempat asal, di mana aktivitas angkutan tersebut dimulai, menuju tempat tujuan, sampai aktivitas pengiriman selesai. Berkaitan dengan hal tersebut, nampak jika komponen pengangkutan terdiri dari muatan yang dibawa, ketersediaan sarana untuk perlengkapan angkut, adanya jalur atau jalan yang bisa dilalui, pemberhentian awal serta terminal tujuan, SDM dan manajemen yang menggerakkan aktivitas transportasi itu (Nasution, 2015:3).

Sarana transportasi merupakan hal penting bagi kehidupan. Pentingnya transportasi tergambar dari makin meningkatnya keperluan akan jasa angkut untuk perpindahan orang juga barang sebagai akibat meningkatnya jumlah penduduk dan pengembangan pemukiman seperti di wilayah Jawa Barat. Berdasarkan data BPS, peningkatan jumlah alat transportasi tahun 2010 hingga tahun 2013 terjadi di setiap moda transportasi yaitu mobil penumpang, bus, truk dan sepeda motor. Jumlah terbesar adalah meningkatnya jumlah sepeda motor sebesar $12,86 \%$. Hal tersebut diduga dengan meningkatnya jumlah alat transportasi, maka kemacetan pun akan meningkat. Kondisi seperti itu seharusnya diimbangi dengan perkembangan panjang jalan untuk menghindari terjadinya kemacetan jalan. Sedangkan perkembangan panjang jalan di Jawa Barat tidak sejalan dengan perkembangan jumlah moda transportasi. Peningkatan panjang jalan tahun 2010 hingga 2013 hanya terjadi pada jalan-jalan kabupaten/kota dengan angka peningkatan sekitar $1,04 \%$ pertahunnya. Sedangkan jalanan nasional serta jalan provinsi tidak mengalami peningkatan. Menurut Nasution (2015:13), moda transportasi yang beroperasi di Indonesia terdiri dari tiga jenis yaitu 1) transportasi udara seperti pesawat terbang, 2) transportasi air seperti kapal laut, dan 3) transportasi darat seperti mobil penumpang, bus, sepeda motor dan kereta api.

PT. Kereta Api Indonesia ialah badan usaha milik negara yang bergerak pada bidang jasa transportasi memiliki tujuan memberikan pelayanan terbaik yang dapat memenuhi harapan penumpang. Dalam menjaga kualitas jasa, dapat dilaksanakan dengan memberi layanan berdasar SPM (Standar Pelayanan Minimum) berdasarkan ketetapan kementrian perhubungan Nomor PM 48 Tahun 2015. Dalam SPM terdapat 6 (enam) dimensi untuk mengukur tingkat pelayanan Kereta Api (KA) Pangrango diantaranya keselamatan, keamanan, kehandalan, kenyamanan, kemudahan dan kesetaraan. Berdasarkan survei awal, yang dilakukan terhadap jumlah penumpang KA Pangrango tahun 2016 diketahui bahwa terjadi penurunan jumlah penumpang pada bulan-bulan tertentu. Hal ini diduga salah satunya belum optimalnya kualitas layanan yang diberikan sehingga berpengaruh pada keputusan penggunaan serta loyalitas konsumen dalam menggunakan jasa angkutan kereta api. Hal tersebut juga menggambarkan terjadi penurunan kepuasan yang dapat berimplikasi terhadap tingkat loyalitas yang juga akan menurun. Berikut data perkembangan total penumpang Kereta Api Pangrango Stasiun Bogor Paledang tahun 2016: 


\section{JUMLAH PENUMPANG KA PANGRANGO}

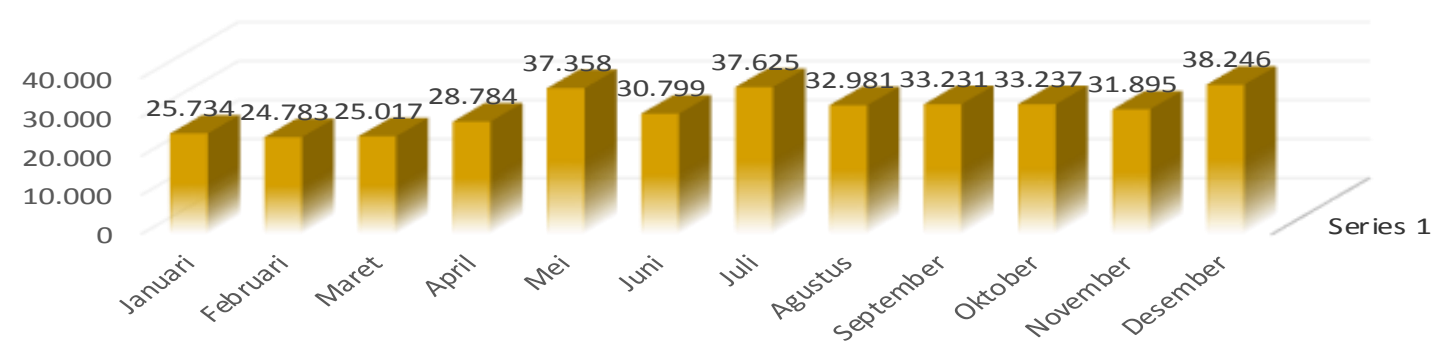

Gambar 1 : Perkembangan Jumlah Penumpang KA Pangrango tahun 2016

Sumber : PT KA Pangrango, 2017

Berdasarkan Gambar 1, penurunan penumpang ini diduga salah satunya dikarenakan kualitas layanan yang diberikan belum dilakukan secara optimal. Kualitas layanan itu meliputi keamanan, keselamatan, kehandalan, kenyamanan dan kemudahan dari jasa transportasi. Karena beberapa hal tersebut dapat mempengaruhi keputusan penggunaan serta loyalitas penumpang pemakai jasa kereta api. Adapun informasi yang diunggah Sindonews.com pada 9/4/2016 mengenai pelayanan KA Pangrango terdapat beberapa keluhan di antaranya adalah AC mengalami kebocoran, toilet di dalam kereta tidak berfungsi dengan baik, dan jalan di depan stasiun becek jika terjadi hujan karena tidak dicor. Oleh karenanya, sangat perlu untuk mempelajari mengenai SPM dikaitkan dengan loyalitas pelanggan, sehingga hal tersebut menjadi menarik untuk diteliti dengan judul "Peningkatan Loyalitas Penumpang Melalui Standar Pelayanan Minimum Pada Kereta Api Pangrango Jalur Bogor-Sukabumi"

\section{MATERI DAN METODE}

Acuan dasar penelitian ini antara lain penelitian dari :

1) Santoso (2013), melakukan penelitian dengan judul Pengaruh Kualitas Pelayanan Terhadap Loyalitas Pelanggan Laboratorium Klinik Populer Surabaya.
Hasil riset menunjukkan simultan variabel bebas terdiri dari bukti fisik, keandalan, jaminan, daya tanggap mempengaruhi signifikasi dan positif pada loyalitas pelanggan Klinik Populer Surabaya. Hasil pengujian parsial menggambarkan kualitas pelayanan terdiri variabel bukti fisik, daya tanggap, kehandalan, empati, jaminan mempengaruhi signifikasi dan positif pada loyalitas pelanggan Klinik Populer Surabaya. Variabel yang mempunyai pengaruh besar ialah bukti fisik.

2) Veronica Diona M.K dan Supriyono (2016) melakukan penelitian tentang Pengaruh Kualitas Pelayanan Terhadap Kepuasan Konsumen Jasa Transportasi Kereta Api Indonesia (KAI) Daerah Operasi 6 Yogyakarta. Hasil Riset menunjukkan bahwa, secara simultan variabel tangible, reliability, responsiveness, emphaty, dan assurance mempengaruhi kepuasan penumpang. Secara parsial, variabel tangible, emphaty, assurance, mempengaruhi kepuasan penumpang. Sedangkan variabel reliability dan responsiveness tidak berpengaruh secara masing-masing pada kepuasan penumpang.

3) Endang Silaningsih, dkk. (2015) melakukan penelitian tentang Transjakarta Company's Strategy And Minimum Service Standard To Raise 
Passengers' Satisfaction. Hasil penelitian menunjukkan, secara simultan SPM (kehandalan, keamanan dan keselamatan, kemudahan, dan kenyamanan) mempengaruhi kepuasan penumpang Transjakarta. Sedangkan secara parsial, dimensi kehandalan dan kenyamanan mempengaruhi kepuasan penumpang. Dimensi keselamatan, keamanan serta kemudahan tidak mempengaruhi kepuasan penumpang.

\section{Standar Pelayanan Minimum (SPM)}

SPM ialah ukuran minimum pelayanan dalam memberikan layanan kepada pengguna jasa sebagai tolak ukur dan pedoman penyelenggaraan pelayanan dan kewajiban yang harus dipenuhi oleh penyedia jasa kepada masyarakat yang meliputi pelayanan berkualitas, cepat, mudah dan terjangkau (Peraturan Menteri Perhubungan No. PM 48 Tahun 2015). SPM dibagi dua bagian yaitu SPM pada stasiun dan SPM dalam Perjalanan dengan dimensi mencakup keselamatan, keamanan, kehandalan, kenyamanan, kemudahan, dan kesetaraan.

\section{Loyalitas Konsumen}

Loyalitas ialah perilaku membeli non random yang diusulkan dari periode ke periode oleh beberapa unit pengambilan keputusan (Griffin, 2007:274). Sedangkan menurut Tjiptono (2011:481), loyalitas ialah sikap pembelian berulang terkait pembelian merek tertentu (bisa karena satu-satunya tersedia, termurah dan sebagainya).

\section{KA Pangrango}

Kereta api Pangrango adalah KA komersial (kelas eksekutif dan ekonomi) jarak menengah yang dimiliki PT. Kereta Api Indonesia dengan relasi Stasiun Bogor Paledang-Stasiun Sukabumi. Kereta api Pangrango diresmikan oleh Menteri BUMN pada 9 November 2013, bersamaan dengan pembukaan Stasiun Bogor Paledang, menggantikan KRD Bumi Geulis yang sudah tidak berfungsi sejak Desember 2012.

Berdasarkan definisi tersebut, dapat dirumuskan kerangka pemikiran dari penelitian tentang pengaruh SPM pada loyalitas penumpang KA Pangrango Stasiun Bogor Paledang :

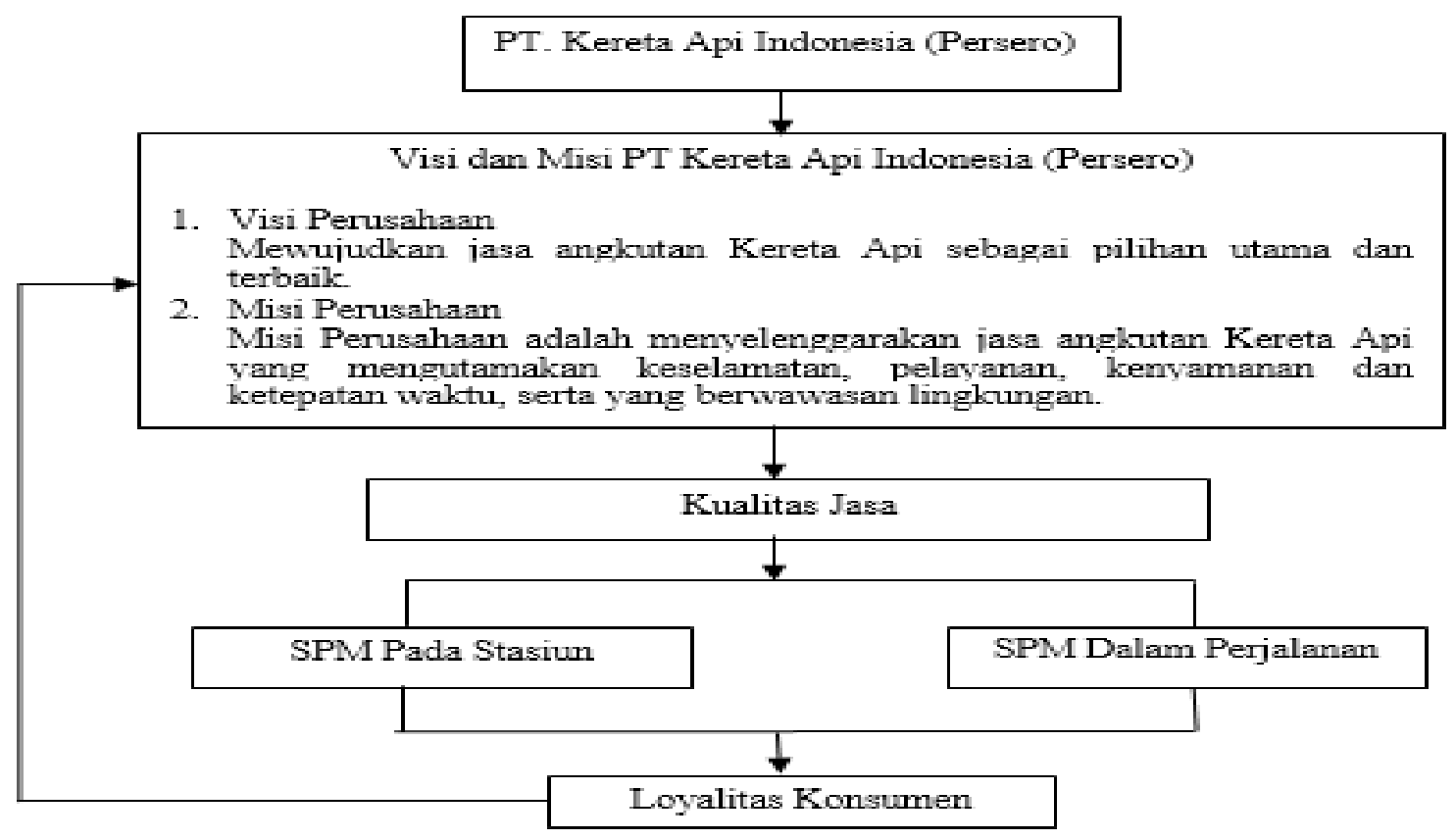

Gambar 2

Kerangka Pemikiran 
Gambar 2 menjelaskan bahwa PT. Kereta Api Indonesia merupakan badan usaha tunggal yang bergerak dalam bidang jasa transportasi. Dalam pengoperasiannya dibagi menjadi sembilan daerah operasi (DAOP) dengan tujuan memberikan pelayanan yang efektif dan efisien karena hanya fokus pada daerah tersebut. Salah satunya adalah kereta api Pangrango jalur Bogor-Sukabumi yang berada dibawah naungan DAOP I Jakarta. PT. Kereta Api Indonesia memiliki visi untuk mewujudkan jasa angkutan kereta api sebagai pilihan utama dan terbaik. Sedangkan, misinya adalah menyelenggarakan jasa angkutan kereta api yang mengutamakan keselamatan, pelayanan, kenyamanan, ketepatan waktu, serta berwawasan lingkungan. Untuk mewujudkan visi dan misi tersebut, upaya yang harus dilakukan adalah menjaga kualitas jasa yang diberikan kepada konsumen (penumpang), salah satunya dengan memberikan pelayanan sesuai dengan Standar Pelayanan Minimum (SPM) yang termuat dalam Peraturan Menteri Perhubungan Nomor PM 48 Tahun 2015. SPM tersebut memiliki dua substansi SPM yaitu; SPM pada Stasiun dan dalam Perjalanan Kereta Api. Standar Pelayanan Minimum tersebut kemudian diimplementasikan pada jasa layanan kereta api, untuk selanjutnya dinilai dan akan menimbulkan tanggapan terhadap kualitas jasa yang diterima oleh konsumen (penumpang) sehingga akan berdampak pada loyalitas konsumen (penumpang).

\section{Pengembangan Hipotesis Penelitian}

SPM ialah referensi PT. KAI dalam memaksimalkan pelayanan kepada penumpang untuk mewujudkan kepuasan untuk membentuk loyalitas dari jasa yang diberikan. Hal tersebut termaktub dalam Peraturan Menteri Perhubungan No. PM 48 Tahun 2015 menyebutkan bahwa SPM ialah referensi bagi penyelenggara perkeretaapian yang mengoperasikan stasiun kereta api dalam menyampaikan layanan pada pemakai jasa kereta api dan penyelenggaraan prasarana perkeretaapian yang mengoperasikan aktivitas angkutan orang dengan kereta api.

\section{Hubungan SPM Pada Stasiun Terhadap Loyalitas Penumpang}

SPM pada stasiun merupakan acuan PT.KAI untuk memaksimalkan pelayanan di dalam stasiun yang meliputi enam aspek diantaranya keselamatan, keamanan, kehandalan, kemudahan, kenyamanan, kesetaraan yang kemudian dikembangkan dalam bentuk pelayanan. Menurut Tjiptono (2011:59), pelayanan yang baik merupakan tingkat keunggulan yang diharapkan dan pengelolaan atas tingkat keunggulan tersebut untuk memenuhi kepuasan konsumen yang tinggi. Jika jasa yang diterima atau dirasakan (perceived service) sesuai dengan yang diharapkan, maka kualitas pelayanan dipersepsikan memuaskan, sehingga akan mempengaruhi tingkat loyalitas konsumen. Sebaliknya jika jasa yang diterima lebih rendah daripada yang diharapkan, maka kualitas pelayanan dipersepsikan buruk sehingga akan berdampak pada menurunnya tingkat loyalitas konsumen. Untuk meningkatkan loyalitas, perusahaan harus mampu meningkatkan kepuasan setiap pelanggan dan mempertahankan tingkat kepuasan tersebut dalam jangka panjang (James G. Barnes,2001). Hal ini sesuai dengan penelitian yang dilakukan oleh Sirhan Fikri, Wahyu, dan Agung (2016) yang menyebutkan bahwa bukti langsung (tangible) sangat berpengaruh signifikan terhadap loyalitas pada mahasiswa Fakultas Ilmu Sosial dan Ilmu Politik Universitas Merdeka Malang.

$\mathrm{H}_{1}$ : SPM pada stasiun berpengaruh positif serta signifikasi pada loyalitas penumpang.

\section{Hubungan SPM dalam perjalanan terhadap loyalitas penumpang}


SPM dalam perjalanan merupakan acuan PT. KAI untuk memaksimalkan pelayanan di dalam kereta selama perjalanan yang meliputi enam aspek diantaranya keselamatan, keamanan, kehandalan, kemudahan, kesetaraan, kenyamanan yang nantinya dikembangkan lebih khusus pada bentuk pelayanan. Konsumen akan mengevaluasi kualitas layanan itu baik atau tidaknya dari penerimaan pelayanan sesuai diharapkan. Karena penumpang merasa puas menerima pelayanan sesuai yang diharapkan. Menurut Griffin (2007:4), konsumen yang loyal adalah konsumen yang selalu membeli kembali dari provider atau penyedia jasa yang sama dan memelihara perilaku positif penyedia jasa dimasa datang. Hal tersebut sesuai dengan penelitian Dessy Pirbadi (2014) yang menyebutkan bahwa Service quality memiliki pengaruh signifikasi juga positif pada loyalitas. SPM dalam perjalanan melibatkan sarana prasarana perkeretaapian lebih intens, karena kepuasan penumpang yang akan dinilai lebih adalah kualitas pelayanan yang diterima oleh penumpang didalam kereta api selama dalam perjalanan termasuk fasilitas yang ada di dalam kereta.

$\mathrm{H}_{2}$ : SPM dalam perjalanan berpengaruh positif serta signifikasi pada loyalitas.

\section{Hubungan SPM pada stasiun dan SPM dalam perjalanan terhadap loyalitas penumpang}

SPM pada stasiun dan SPM dalam perjalanan merupakan variabel yang menentukan tingkat kepuasan penumpang dan memiliki pengaruh besar terhadap loyalitas. Untuk perusahaan jasa, kualitas layanan adalah bentuk aktualisasi nyata secara fisik dapat terlihat atau digunakan oleh pegawai sesuai dengan penggunaan dan pemanfaatannya yang dapat dirasakan membantu pelayanan yang diterima oleh orang yang menginginkan pelayanan, sehingga puas atas pelayanan yang dirasakan, yang sekaligus menunjukkan prestasi kerja atas pemberian pelayanan yang diberikan (Pasuraman, 2001). Hal ini sesuai dengan penelitian Ketut Ngurah Darma A. (2013) yang menyebutkan bahwa Kualitas layanan berpengaruh positif dan signifikan terhadap kepuasan pelanggan Garuda Indonesia dengan koefisien sebesar 0,395. Kepuasan berpengaruh positif dan signifikan terhadap loyalitas pelanggan Garuda Indonesia dengan koefisien sebesar 0,212. Dan kualitas layanan berpengaruh positif dan signifikan terhadap loyalitas pelanggan Garuda Indonesia dengan koefisien sebesar 0,338. Hal ini berarti bahwa semakin baik kualitas layanan yang diberikan maka loyalitas pelanggan akan meningkat.

$\mathrm{H}_{3}$ : SPM pada stasiun dan SPM dalam perjalanan mempengaruhi positif serta signifikasi loyalitas.

\section{Desain Penelitian}

Metode penelitian yang digunakan adalah deskriptif dan verifikatif. Penelitian deskriptif adalah penelitian yang menggambarkan apa yang dilakukan oleh perusahaan berdasarkan faktor-faktor yang ada, kemudian diolah menjadi data dan dianalisis untuk memperoleh suatu kesimpulan (Mashuri, 2008). Sedangkan, penelitian verifikatif adalah penelitian yang bertujuan untuk memeriksa benar atau tidaknya apabila dijelaskan untuk menguji suatu cara dengan atau tanpa perbaikan yang telah dilaksanakan di tempat lain dengan mengatasi masalah yang serupa dengan kehidupan (Mashuri, 2008). Pengambilan sampel dengan mengambil beberapa sampel dari populasi dan menggunakan kuisioner sebagai alat pengumpulan data utama (Supranto, 2001).

\section{Populasi, Sampel dan Teknik Pengambilan Sampel}

Populasi penelitian adalah penumpang kereta api Pangrango Stasiun Bogor Paledang. Sampel memakai teknik sampling nonprobability yaitu purposive sampling 
yang merupakan teknik sampel berdasar kriteria tertentu bertujuan agar data yang diperoleh nantinya bisa lebih representatif (Sugiyono, 2016:85). Untuk meneliti variabel loyalitas, responden harus pernah melaksanakan pembelian ulang. Kriteria sampel adalah: pengguna KA Pangrango yang melakukan perjalanan dengan rute Bogor-Sukabumi, dan perjalanan tersebut sudah dilakukan lebih dua kali. Besarnya sampel merujuk pada pendapat Alreck dan Seetle yang dikutip Suharsaputra (2012:119), menjelaskan bahwa untuk populasi yang besar, minimal sampel kira-kira 100 responden dan maksimal 1000 responden atau $10 \%$ kisaran angka minimum dan maksimum. Dalam penelitian ini menggunakan sampel sebanyak 100 responden.

\section{Operasional Variabel}

Variabel yang dianalisis adalah variabel bebas yaitu SPM pada Stasiun $\left(\mathrm{X}_{1}\right)$ dan SPM dalam perjalanan $\left(\mathrm{X}_{2}\right)$ dan variabel terikat ialah loyalitas penumpang (Y). Adapun operasionalisasi variabel dalam riset ini adalah :

Tabel 1. Operasional Variabel

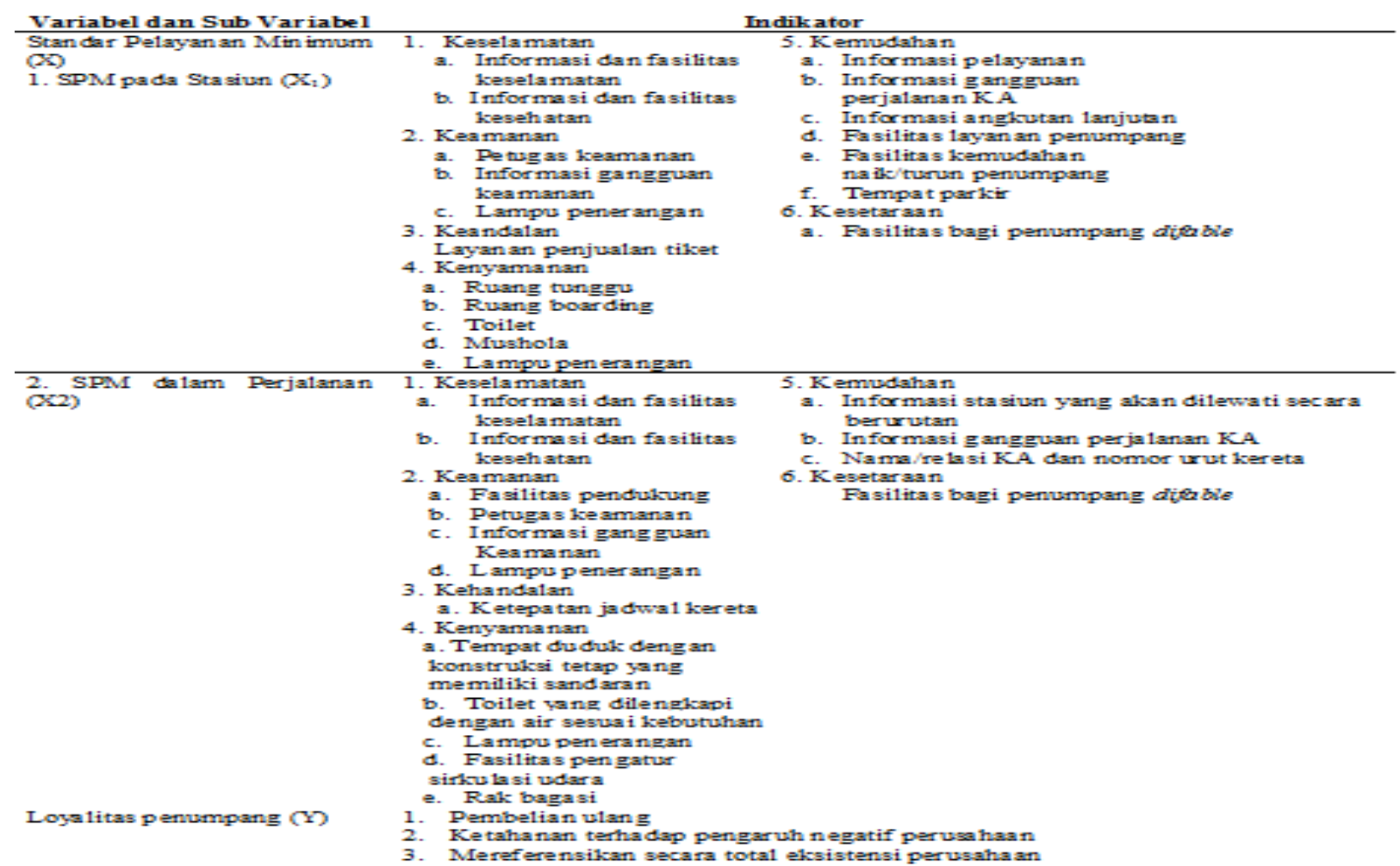

\section{Jenis dan Sumber Data}

Jenis data penelitian adalah kuantitatif dan kualitatif. Sedangkan sumber data berasal dari data primer dan sekunder. Sebelum diolah dan dikaji dilaksanakan uji terhadap kualitas data guna memahami ketekunan responden menjawab pertanyaan, yakni uji validitas serta reliabilitas. Uji validitas menggunakan rumus korelasi product moment. Jika didapatkan $\mathrm{r}_{\text {hitung }}>$ $r_{\text {tabel }}$ data dinyatakan valid dan layak untuk dipakai uji hipotesis, sedangkan jika $\mathrm{r}_{\text {hitung }}<$ $r_{\text {tabel }}$ data dinyatakan tidak valid, artinya tidak bisa dipakai uji hipotesis. Uji reliabilitas menggunakan Cronbanch Alpha. Jika intrumen melebihi atau sama dengan 0,6 $(\geq 0,6)$ maka intrumen dinyatakan reliabel

\section{Metode Analisis dan Langkah- Langkahnya}


Metode analisis data memakai uji statistika dimana sebelumnya diolah dengan memakai skala Likert (1-5) dengan interpretasi sangat tidak setuju sampai dengan sangat setuju. Kriteria penilaian dalam penelitian adalah sangat setuju: dengan skor 5 , setuju : 4 , netral: 3 , tidak setuju:2 dan sangat tidak setuju :1 (Sugiyono, 2016:93). Untuk mengetahui ada atau tidaknya pengaruh SPM terhadap loyalitas penumpang, dapat memakai analisis regresi linier berganda dengan persamaan:

$\mathrm{Y}=\alpha+\beta_{1} \mathrm{X}_{1}+\beta_{2} \mathrm{X}_{2}+\varepsilon$.

Dimana: $Y=$ Loyalitas penumpang, $\mathrm{X}_{1}=$ SPM Pada Stasiun, $X_{2}=$ SPM dalam Perjalanan, $\alpha=$ Konstanta, $\beta_{1}=$ Koefisen regresi untuk mengetahui sejauh mana pengaruh SPM pada stasiun terhadap loyalitas penumpang, $\beta_{2}=$ Koefisen regresi untuk mengetahui sejauh mana pengaruh SPM dalam perjalanan terhadap loyalitas penumpang, $\quad \varepsilon=$ Faktor lain. Untuk mengetahui kekuatan hubungan antara SPM pada loyalitas penumpang maka digunakan rumus sebagai berikut :

$r X i Y=\frac{\left.n\left(\sum X i Y\right)-\left(\sum X i\right) \sum Y\right)}{\sqrt{ }\left(n \sum X^{2}-\left(\sum X\right)^{2}\right)\left(\mathrm{n} \sum Y^{2}-\left(\sum Y\right)\right)}$

Dari rumus analisis korelasi di atas, maka akan diperoleh nilai $r$ yang besarnya antara $-1,0$ sampai 1. Notasi ini menggunakan korelasi atau keterkaitan variabel yang diuji dalam penelitian. Jika $r=$ 0 atau mendekati 0 , tidak ada hubungan kedua variabel atau hubungan variabel sangat lemah; Jika $r=1$ atau mendekati 1, hubungan kedua variabel bersifat searah dan sangat kuat, artinya kenaikan nilai-nilai $\mathrm{X}$ akan diikuti oleh kenaikan nilai-nilai $\mathrm{Y}$, atau sebaliknya. Jika $r=-1$ atau mendekati -1 , hubungan kedua variabel berlawanan arah dan sangat kuat, artinya kenaikan nilai-nilai $\mathrm{X}$ akan diikuti oleh penurunan nilai-nilai $\mathrm{Y}$, atau sebaliknya. Untuk melihat besarnya kontribusi variasi SPM terhadap variasi loyalitas penumpang dapat menggunakan analisis koefisien determinasi. Menurut
Sugiyono (2014:257) koefisien determinasi dihitung dengan rumus $: \mathrm{KD}=r^{2} \times 100 \%$.

Untuk mengetahui kebenaran dari perhitungan analisis regresi, maka diperlukan pengujian hipotesis nol $(\mathrm{Ho})$ dan hipotesis alternatif (Ha). Maka digunakan uji $\mathrm{F}$ dan Uji-t. Pengujian ini menggunakan distribusi t, dengan keyakinan (1- $\alpha$ ) sebesar $95 \%$ dan derajat kebebasan sebesar n-3-1 untuk menguji apakah hipotesis diterima atau ditolak.

\section{Uji F}

Uji hipotesis untuk mengetahui pengaruh secara simultan variabel bebas terhadap variabel terikat yaitu dengan melihat hasil uji F. Rumus yang digunakan adalah :

$$
F_{\text {hitung }}=\frac{R^{2} / k}{\left(1-R^{2}\right) /(n-k-1)}
$$

Kriteria uji F :

1) Bila $F_{\text {hitung }} \leq F_{\text {tabel, }}$ pada $\alpha=0,05, \mathrm{H}_{0}$ diterima dan $\mathrm{H}_{\mathrm{a}}$ ditolak, artinya SPM pada stasiun dan dalam perjalanan tidak mempengaruhi signifikan dan positif secara simultan pada loyalitas penumpang.

2) Bila $F_{\text {hitung }}>F_{\text {tabel, }}$ pada $\alpha=0,05, \mathrm{H}_{0}$ ditolak dan $\mathrm{H}_{\mathrm{a}}$ diterima, artinya SPM pada Stasiun dan dalam Perjalanan mempengaruhi signifikan dan positif secara simultan pada loyalitas penumpang.

\section{Uji-t}

Uji parsial untuk menganalisis pengaruh tiap-tiap variabel bebas terhadap variabel terikat., adapun rumusnya adalah :

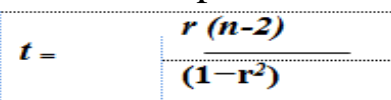

Kriteria Keputusan Uji-t ;

Adapun kriteria uji signifikan dari kedua variabel :

1. Untuk SPM pada Stasiun bila $t_{\text {hitung }} \leq t_{\text {tabel }}$ pada $\alpha=0,05, \mathrm{H}_{0}$ diterima serta $\mathrm{H}_{\mathrm{a}}$ ditolak, artinya SPM pada Stasiun $\left(\mathrm{X}_{1}\right)$ tidak berpengaruh positif serta signifikasi pada loyalitas penumpang (Y). 
Sedangkan, bila $\mathrm{t}_{\text {hitung }}>\mathrm{t}_{\text {tabel }}$ pada $\alpha=$ 0,05 maka $\mathrm{H}_{\mathrm{a}}$ diterima artinya SPM pada Stasiun $\left(\mathrm{X}_{1}\right)$ berpengaruh positif dan signifikasi pada loyalitas penumpang (Y)

2. Untuk SPM dalam perjalanan bila $t_{\text {hitung }} \leq$ $t_{\text {tabel }}$ pada $\alpha=0,05, \mathrm{H}_{0}$ diterima dan $\mathrm{H}_{\mathrm{a}}$ ditolak, artinya SPM dalam Perjalanan $\left(\mathrm{X}_{2}\right)$ tidak punya pengaruh positif dan signifikasi pada loyalitas penumpang $(\mathrm{Y})$. Sedangkan bila $t_{\text {hitung }}>t_{\text {tabel }}$ pada $\alpha=0,05$ maka $\mathrm{H}_{\mathrm{a}}$ diterima artinya SPM dalam
Perjalanan $\left(\mathrm{X}_{2}\right)$ mempengaruhi signifikasi dan positif pada loyalitas penumpang (Y).

\section{HASIL DAN PEMBAHASAN}

\section{Karakteristik Penumpang}

Karakteristik penumpang pengguna jasa kereta api Pangrango stasiun Bogor Paledang yang menjadi sampel digambarkan pada tabel berikut:

\section{Tabel 2. Karakteristik Penumpang}

\begin{tabular}{|c|c|c|c|c|}
\hline No & Karakteristik & $\begin{array}{c}\text { Ciri-ciri } \\
\text { Penumpang }\end{array}$ & $\begin{array}{c}\text { Jumlah } \\
\text { Penumpang }\end{array}$ & $\%$ \\
\hline 1 & Jenis Kelamin & Perempuan & 57 & 57 \\
\hline 2 & Umur & $17-26$ tahun & 61 & 61 \\
\hline 3 & Pendidikan & Sarjana $(\mathrm{S} 1 / \mathrm{S} 2 / \mathrm{S} 3)$ & 42 & 42 \\
\hline 4 & Pekerjaan & Pegawai Swasta & 49 & 49 \\
\hline 5 & Penghasilan & Diatas Rp. 3.000.000 & 49 & 49 \\
\hline 6 & Keperluan Perjalanan & Bekerja & 42 & 42 \\
\hline 7 & Frekwensi Perjalanan & 5 kali per minggu & 82 & 82 \\
\hline 8 & $\begin{array}{l}\text { Akses Kendaraan yang Digunakan Untuk Menuju } \\
\text { Stasiun }\end{array}$ & Angkutan Kota & 41 & 41 \\
\hline 9 & Alternatif yang Digunakan Selain KA Pangrango & Angkutan Kota & 38 & 38 \\
\hline 10 & $\begin{array}{l}\text { Alasan Menggunakan Alternatif Kendaraan Lain } \\
\text { Selain KA Pangrango }\end{array}$ & $\begin{array}{l}\text { Lainnya (Kehabisan } \\
\text { Tiket Kereta) }\end{array}$ & 37 & 37 \\
\hline 11 & Domisili & Sukabumi & 72 & 72 \\
\hline
\end{tabular}

Sumber : data diolah, 2017

Berdasarkan Tabel 2 tersebut, karakteristik penumpang mayoritas berjenis kelamin perempuan berusia 17-26 tahun berpendidikan sarjana (S1/S2/S3) dengan pekerjaan mayoritas pegawai swasta dan berpenghasilan diatas Rp. 3.000.000/bulan. Keperluan perjalanannya adalah untuk bekerja dengan frekuensi perjalanan 5 kali per minggu. Kendaraan yang dipakai menuju stasiun menggunakan angkutan kota. Alternatif kendaraan yang digunakan selain KA Pangrango adalah angkutan kota dengan alasan jika dikarenakan kehabisan tiket kereta dan responden mayoritas berdomisili di Sukabumi.

\section{Tanggapan Penumpang Terhadap Kualitas SPM Pada Stasiun Bogor Paledang}

Tanggapan penumpang meliputi SPM di PT. KA Pangrango pada stasiun, SPM di PT. KA Pangrango dalam perjalanan, dan tanggapan loyalitas penumpang.

SPM pada stasiun meliputi indikator diantaranya keselamatan, keamanan, kehandalan, kenyamanan, kemudahan, dan kesetaraan. Berikut adalah tabel tanggapan penumpang terhadap SPM di stasiun :

\section{Tabel 3. Rekapitulasi Tanggapan Penumpang Terhadap SPM Pada Stasiun Bogor Paledang}




\begin{tabular}{|c|c|c|c|}
\hline No & Uraian & $\begin{array}{c}\text { Penilaian } \\
\text { penumpang }\end{array}$ & Keterangan \\
\hline 1 & Informasi fasilitas keselamatan & 3,69 & Mudah terlihat dan terjangkau \\
\hline 2 & Informasi fasilitas kesehatan & 3,41 & Mudah terlihat dan terjangkau \\
\hline 3 & Petugas keamanan & 3,55 & Tersedia dan Terlihat \\
\hline 4 & Informasi gangguan keamanan & 3,77 & Mudah terlihat dan jelas terbaca \\
\hline 5 & Lampu penerangan terhadap keamanan & 3,64 & Terang \\
\hline 6 & Layanan penjualan tiket & 3,66 & Sesuai \\
\hline 7 & Ruang tunggu & 3,69 & Luas dan terawat \\
\hline $\mathrm{s}$ & Ruang boarding & 3,48 & Luas, bersih dan terawat \\
\hline 9 & Toilet & 3,53 & Memadai, bersih dan terawat \\
\hline 10 & Mushola & 3,57 & Mema dai, bersih dan terawat \\
\hline 11 & Lampu penerangan terha dap kenyamanan & 3,70 & Terang \\
\hline 12 & Informasi pelayanan & 3,78 & Tersedia \\
\hline 13 & Informasi gangguan perjalanan kereta api & 3,82 & Sesuai \\
\hline 14 & Informasi angkutan lanjutan & 3,63 & Mudah terlihat dan jelas terbaca \\
\hline 15 & Fa silitas layanan penumpang & 3,68 & Memadai \\
\hline 16 & Fa silitas kemudahan naik/turum penumpang & 3,73 & Memadai \\
\hline 17 & Tempat parkir & 3,51 & Luas danlancar \\
\hline 18 & Fasilitas bagi penumpang difable & 3,51 & Sesuai \\
\hline \multicolumn{2}{|r|}{ Rata-rata penilaian responden terhadap SPM } & 3,63 & Sesuai SPM \\
\hline
\end{tabular}

Berdasarkan Tabel 3 tersebut, rekapitulasi rata-rata SPM pada stasiun Bogor Paledang adalah 3,63 atau berada pada range 3,40-4,20 dengan interpretasi sesuai SPM. Nilai SPM pada stasiun Bogor Paledang tertinggi adalah atribut informasi gangguan perjalanan kereta api sebesar 3,82 dengan interpretasi sesuai yaitu penyampaian informasi gangguan perjalanan kereta api 11-20 menit setelah terjadi gangguan. Untuk memaksimalkan pelayanan kepada penumpang sebaiknya ditingkatkan lagi penyampaian informasi menjadi lebih cepat $<10$ menit. Nilai SPM di stasiun Bogor
Paledang yang memiliki nilai terendah adalah pada atribut informasi fasilitas kesehatan sebesar 3,41 dengan interpretasi mudah terlihat dan terjangkau.

\section{Tanggapan Penumpang Terhadap SPM Dalam Perjalanan Kereta Api}

Standar Pelayanan Minimum (SPM) dalam perjalanan meliputi indikator diantaranya keselamatan, keamanan, kehandalan, kenyamanan, kemudahan, dan kesetaraan. Berikut adalah tanggapan penumpang terhadap SPM dalam perjalanan:

Tabel 4. Rekapitulasi Tanggapan Penumpang Terhadap SPM Dalam Perjalanan

\begin{tabular}{clcl}
\hline No & \multicolumn{1}{c}{ Uraian } & $\begin{array}{c}\text { Penilaian } \\
\text { penumpang }\end{array}$ & \multicolumn{1}{c}{ Keterangan } \\
\hline 1 & Informasi dan fasilitas keselamatan & 3,74 & Mudah terlihat dan terjangkau \\
2 & Informasi dan fasilitas kesehatan & 3,89 & Mudah terlihat dan terjangkau \\
3 & Fasilitas pendukung & 3,68 & Memadai \\
4 & Petugas keamanan & 3,98 & Sesuai \\
5 & Informasi gangguan keamanan & 4,19 & Memadai \\
6 & Lampu penerangan terhadap keamanan & 4,26 & Sangat Terang \\
7 & Ketepatan jadwal kereta api & 4,24 & Sangat Sesuai \\
8 & Tempat duduk dengan konstruksi tetap yang & 4,22 & Sangat Tersedia \\
& memiliki sandaran & & \\
9 & Toilet dilengkapi dengan air sesuai & 3,88 & Bersih dan memadai \\
& kebutuhan & & \\
10 & Lampu penerangan terhadap kenyamanan & 3,93 & Terang \\
11 & Fasilitas pengatur sirkulasi udara & 4,16 & Memadai \\
12 & Restorasi & 3,89 & Mencukupi \\
13 & Rak bagasi & 4,27 & Sangat Mencukupi \\
14 & Informasi stasiun yang akan dilewati secara & 4,09 & Strategis dan jelas terdengar \\
& berurutan & & \\
15 & Informasi gangguan perjalanan kereta api & 3,82 & Sesuai \\
16 & Nama/relasi KA dan nomor urut kereta & 3,72 & Tersedia \\
17 & Fasilitas bagi penumpang difable & 3,87 & Tersedia \\
\hline Rata-rata penilaian responden terhadap SPM & $\mathbf{3 . 9 9}$ & Sesuai SPM \\
\multicolumn{2}{c}{ dalam perjalanan } & & \\
\hline
\end{tabular}

Sumber : data diolah, 2017 
Berdasarkan tabel 4 diatas, rekapitulasi rata-rata SPM dalam perjalanan adalah 3,99 atau berada pada range 3,40-4,20 dengan interpretasi sesuai SPM. Nilai SPM dalam perjalanan tertinggi adalah atribut rak bagasi sebesar 4,27 dengan interpretasi sangat tersedia artinya tersedia rak bagasi disetiap atas tempat duduk yang berfungsi untuk menyimpan barang sehingga tidak mengganggu kenyamanan penumpang dan nilai SPM dalam perjalanan terendah adalah pada atribut fasilitas pendukung sebesar 3,68 dengan interpretasi memadai yaitu memiliki 1 CCTV setiap gerbong.

Tanggapan Penumpang Terhadap Loyalitas Konsumen Di Kereta Api Pangrango Stasiun Bogor Paledang

Berikut adalah tanggapan penumpang terhadap loyalitas:

Tabel 5. Rekapitulasi Tanggapan Penumpang Terhadap Loyalitas

\begin{tabular}{|c|c|c|c|}
\hline No & Uraian & $\begin{array}{c}\text { Penilaian } \\
\text { penumpang }\end{array}$ & Keterangan \\
\hline \multirow[t]{2}{*}{1} & Selalu menggunakan KA & 4,01 & KA Pangrango dapat memnuhi kebutuhan \\
\hline & $\begin{array}{l}\text { Pangrango ketika melewati } \\
\text { rute Bogor-Sukabumi }\end{array}$ & & $\begin{array}{l}\text { transportasi dalam melakukan aktivitas sehari- } \\
\text { hari }\end{array}$ \\
\hline 2 & $\begin{array}{l}\text { Tidak terpengaruh oleh } \\
\text { kondisi kereta api dan } \\
\text { informasi negatif tentang } \\
\text { KA Pangrango }\end{array}$ & 3,82 & $\begin{array}{l}\text { KA Pangrango merupakan alat transportasi yang } \\
\text { lebih cepat daripada alat transportasi lain dan } \\
\text { tidak akan mengalami kemacetan }\end{array}$ \\
\hline \multirow[t]{2}{*}{3} & Selalu merekomendasikan & 3,88 & KA Pangrango memiliki keunggulan daripada \\
\hline & $\begin{array}{l}\text { KA Pangrango kepada } \\
\text { orang lain }\end{array}$ & & $\begin{array}{l}\text { alat transportasi lain yaitu lebih cepat dan tidak } \\
\text { akan mengalami kemacetan dan dapat memnuhi } \\
\text { kebutuhan transportasi dalam melakukan } \\
\text { aktivitas sehari-hari }\end{array}$ \\
\hline & $\begin{array}{l}\text { ata penilaian penumpang } \\
\text { dap loyalitas konsumen }\end{array}$ & & \\
\hline
\end{tabular}

Sumber : data diolah, 2017

Berdasarkan tabel 5 tersebut, rekapitulasi rata-rata loyalitas penumpang adalah 3,90 atau berada pada range 3,40-4,20 dengan interpretasi setuju. Nilai loyalitas penumpang tertinggi adalah atribut selalu menggunakan KA Pangrango ketika melewati rute Bogor-Sukabumi sebesar 4,01 dengan interpretasi setuju dan nilai loyalitas konsumen terendah adalah pada atribut tidak terpengaruh oleh kondisi kereta api juga informasi negatif tentang KA Pangrango sebesar 3,82 dengan interpretasi Setuju.
Pengaruh Standar Pelayanan Minimum (SPM) Secara Simultan Dan Parsial Terhadap Loyalitas Penumpang

Bentuk persamaan dapat dihitung dengan menggunakan analisis regresi berganda. Adapun persamaan tersebut adalah untuk menunjukkan pengaruh SPM pada stasiun dan SPM dalam perjalanan terhadap loyalitas penumpang di Stasiun Bogor Paledang.

\section{Analisis Regresi Berganda}

Hasil perhitungan keterikatan fungsional dengan memakai analisis regresi diperoleh hasil pada Tabel 6 sebagai berikut:

Tabel 6. Koefisien Regresi dan Uji Signifikasi Coeficients

\begin{tabular}{lccccc}
\multicolumn{1}{c}{ Model } & \multicolumn{2}{c}{$\begin{array}{c}\text { Coeficients } \\
\text { Unstandardized } \\
\text { Coefficients }\end{array}$} & $\begin{array}{c}\text { Standardized } \\
\text { Coefficients }\end{array}$ & \multirow{2}{*}{ T } & Sig. \\
\cline { 2 - 5 } & $\mathbf{B}$ & Std. Error & Beta & & \\
\hline I (Constant) & $\mathbf{1 , 2 2 4}$ &, 721 & & 1,699 &, 093 \\
SPM Pada Stasiun &, 032 &, 014 &, 160 & 2,372 &, 020 \\
SPM Dalam Perjalanan &, 160 &, 014 &, 748 & 11,125 &, 000 \\
\hline
\end{tabular}

a. Dependent Variable: Loyalitas Penumpang

Sumber : data diolah, 2017 
Berdasarkan Tabel 6 tersebut maka diperoleh suatu persamaan regresi dengan model taksiran sebagai berikut

$Y=1,224+0,032 X_{1}+0,160 X_{2}+\varepsilon$. Dari persamaan regresi tersebut diketahui bahwa :

$\beta_{1}=0,032$ menunjukkan bahwa SPM pada stasiun berpengaruh positif terhadap loyalitas, artinya setiap kenaikan kualitas SPM pada stasiun akan diikuti dengan kenaikan loyalitas penumpang (Y).

$\beta_{1=0,160}$ menunjukkan bahwa SPM dalam perjalanan berpengaruh positif terhadap loyalitas, artinya setiap kenaikan kualitas SPM dalam perjalanan akan diikutidengan kenaikan loyalitas penumpang $(\mathrm{Y})$.

\section{Analisis Korelasi Berganda}

Dari hasil pengolahan data SPSS diperoleh nilai $\mathrm{r}=0,858$ artinya keterikatan variabel SPM pada stasiun dan SPM dalam perjalanan dengan loyalitas penumpang sangat kuat dan searah.

\section{Pengujian Koefisien Regresi}

Sebelum digunakan sebagai dasar kesimpulan, perlu diuji koefisien regresinya baik secara simultan maupun parsial.

\section{a) Pengujian Model Regresi Secara Simultan (Uji F)}

Kriteria pengambilan keputusan Uji $F$, jika $F_{\text {hitung }}>F_{\text {tabel }}$ maka variabel SPM pada stasiun $\left(\mathrm{X}_{1}\right)$ dan SPM dalam perjalanan $\left(\mathrm{X}_{2}\right)$ mempengaruhi loyalitas penumpang $(\mathrm{Y})$, jika $\mathrm{F}_{\text {hitung }} \leq$ $\mathrm{F}_{\text {tabel }}$ maka variabel tidak berpengaruh secara simultan. Untuk melihat pengaruh SPM pada stasiun $\left(\mathrm{X}_{1}\right)$ dan SPM dalam perjalanan $\left(\mathrm{X}_{2}\right)$ pada loyalitas penumpang (Y) secara statistik akan diuji hipotesis sebagai berikut :

Ho : $\beta \mathrm{i} \leq 0$ Tidak terdapat pengaruh positif dan signifikasi simultan SPM pada stasiun dan SPM dalam perjalanan terhadap loyalitas penumpang.

$\mathrm{Ha}: \beta \mathrm{i}>0$ Terdapat pengaruh positif dan signifikasi simultan SPM pada stasiun dan SPM dalam perjalanan terhadap loyalitas penumpang.

Untuk menguji hipotesis statistik tersebut diatas digunakan statistik Uji $\mathrm{F}$ yang diperoleh tabel analisis varians (Anova) sebagai berikut:

\section{Tabel 7. Hasil Uji Terhadap Koefisien Regresi Secara Simultan}

\begin{tabular}{ccccccc}
\multicolumn{8}{c}{ ANOVA $^{\mathbf{a}}$} \\
\hline Model & Sum of Square & DF & Mean Square & F & Sig. \\
\hline I & Regression & 224,264 & 2 & 112,132 & 135,407 & $0,000^{\mathrm{b}}$ \\
Residual & 80,326 & 97 & 0,828 & & \\
Total & 304,590 & 99 & & & \\
\hline
\end{tabular}

a. Dependent Variable: Loyalitas Penumpang (Y)

b. Redictors: (Constant), SPM dalam Perjalanan (X2), SPM pada Stasiun (X1)

Sumber : data diolah, 2017

Berdasarkan nilai $\mathrm{F}$ pada Tabel 7 tersebut $F_{\text {hitung }}$ sebesar 135,407 dan nilai $\mathrm{F}_{\text {tabel }}$ untuk $\mathrm{a}=0,05$ dengan derajat kebebasan $\mathrm{DF}_{1}=3-1=2$ dan $\mathrm{DF}_{2}=100$ $2-1=97$ sebesar 3,15 yang dimana bisa dilihat bahwa 135,407>3,15 maka dapat disimpulkan $\mathrm{H}_{\mathrm{a}}$ diterima dan $\mathrm{H}_{0}$ ditolak 
artinya dengan tingkat kepercayaan 95\% variabel independent SPM pada stasiun $\left(\mathrm{X}_{1}\right)$, SPM dalam perjalanan $\left(\mathrm{X}_{2}\right)$ mempengaruhi positif dan signifikasi simultan pada variabel dependent loyalitas penumpang (Y). Hal ini sesuai dengan penelitian dari Hatane Semuel dan Nadya Wijaya (2009), ada pengaruh positif secara signifikan antara servqual terhadap kepuasan, serta kepuasan bisa jadi mediasi servqual serta Perceived value pada loyalitas. b) Pengujian Model Regresi Secara Parsial (Uji-t)

Uji-t dilakukan dengan membandingkan $t_{\text {hitung }}$ dengan $t_{\text {tabel. }}$ Jika $t_{\text {hitung }}$ lebih besar dari $t_{\text {tabel }}\left(t_{\text {hitung }}>t_{\text {tabel }}\right)$ maka menunjukkan bahwa variabel independent berpengaruh secara parsial terhadap variabel dependent. Untuk lebih jelas, hasil uji-t dapat dilihat pada tabel berikut:

\section{Tabel 8. Koefisien Regresi dan Uji Signifikansi Coeficients}

\begin{tabular}{|c|c|c|c|c|c|}
\hline \multirow[t]{2}{*}{ Model } & \multicolumn{2}{|c|}{$\begin{array}{l}\text { Unstandardized } \\
\text { Coefficients }\end{array}$} & $\begin{array}{c}\text { Standardized } \\
\text { Coefficients }\end{array}$ & \multirow[t]{2}{*}{$\mathbf{T}$} & \multirow[t]{2}{*}{ Sig. } \\
\hline & $\mathbf{B}$ & Std. Error & Beta & & \\
\hline I (Constant) & 1,224 &, 721 & & 1,699 &, 093 \\
\hline SPM Pada Stasiun &, 032 & 014 &, 160 & 2,372 &, 020 \\
\hline SPM Dalam Perjalanan &, 160 & 014 &, 748 & 11,125 &, 000 \\
\hline
\end{tabular}

Sumber : Data Primer, Diolah (2017)

Pengaruh SPM Pada Stasiun $\left(\mathrm{X}_{1}\right)$ Terhadap Loyalitas Penumpang (Y)

Untuk mengetahui ada atau tidaknya pengaruh SPM pada stasiun $\left(\mathrm{X}_{1}\right)$ pada loyalitas konsumen secara statistik akan diuji hipotesisnya sebagai berikut:

$\mathrm{Ho}_{1}: \beta_{1} \leq 0 \quad$ Berarti SPM pada stasiun tidak mempengaruhi positif dan signifikasi pada loyalitas penumpang.

$\mathrm{Ha}_{1}: \beta_{1}>0 \quad$ Berarti SPM pada stasiun berpengaruh positif dan signifikan terhadap loyalitas penumpang.

Berdasarkan pengertian tersebut bahwa $t_{\text {hitung }}$ pada variabel SPM pada stasiun $\left(\mathrm{X}_{1}\right)$ sebesar 2,372 dan nilai $\mathrm{t}_{\text {tabel }}$ untuk $a=0,05$ dengan derajat kebebasan 100-2-1 = 97 sebesar 1,645 berarti 2,372 > 1,645. Maka $\mathrm{H}_{\mathrm{a}}$ diterima dan $\mathrm{H}_{0}$ ditolak, artinya SPM pada stasiun $\left(\mathrm{X}_{1}\right)$ mempengaruhi secara positif dan signifikasi pada loyalitas penumpang (Y). Hasl tersebut sesuai dengan hasil riset dari Agung Muhammad Arifin, Dwi Gemina, dan
Endang Silaningsih (2015) bahwa terdapat 9 (sembilan) atribut SPM yang harus diprioritaskan untuk memperoleh perhatian PT. Transjakarta. Atribut tersebut antara lain keamanan halte, keselamatan di halte, keselamatan dalam bus, keselamatan di koridor, kemudahan pembelian tiket, kebersihan halte, kebersihan lantai maupun interior halte, kebersihan jendela, kebersihan bus dan lantai bus, waktu tunggu penumpang, penguasaan pramudi, keramahan pramudi dan keramahan call center. Untuk kepuasan penumpang (CSI) kategori puas dengan nilai $74 \%$. Berikut adalah hasil uji-t koefisien variabel SPM pada stasiun $\left(\mathrm{X}_{1}\right)$ :

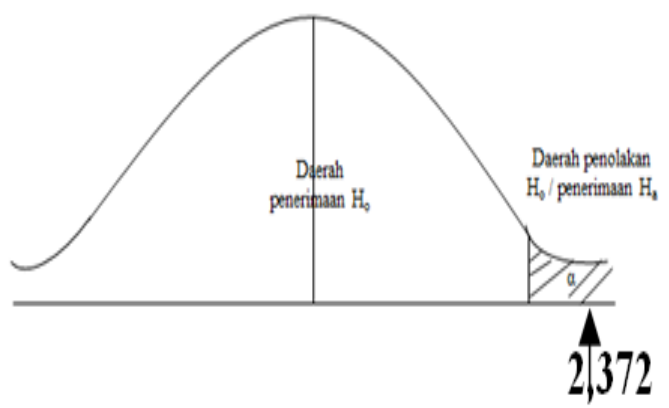

Gambar 3. Hasil Uji-t Koefisien Regresi Variabel SPM Pada Stasiun $\left(X_{1}\right)$

Sumber : Data diolah, 2017 
Pengaruh SPM dalam Perjalanan $\left(\mathrm{X}_{2}\right)$ Pada Loyalitas Penumpang (Y)

Untuk mengetahui ada atau tidaknya pengaruh SPM dalam perjalanan $\left(\mathrm{X}_{2}\right)$ pada loyalitas konsumen secara statistik akan diuji hipotesisnya sebagai berikut:

$\begin{array}{rlr}\mathrm{Ho}_{2}: \beta_{2} \leq 0 & \begin{array}{l}\text { Berarti SPM } \\ \text { perjalanan }\end{array} & \text { dalam } \\ & \text { mempengaruhi } & \text { secara } \\ & \text { positif serta } & \text { signifikasi } \\ & \text { pada } & \text { loyalitas } \\ & \text { penumpang. }\end{array}$

$\mathrm{Ha}_{2}: \beta_{2}>0$ Berarti SPM dalam perjalanan mempengaruhi secara positif serta signifikan pada loyalitas penumpang.

Berdasarkan pengertian tersebut bahwa $t_{\text {hitung }}$ pada variabel SPM dalam perjalanan $\left(\mathrm{X}_{2}\right)$ sebesar 11,125 dan nilai $\mathrm{t}_{\text {tabel }}$ untuk $\mathrm{a}=0,05$ dengan derajat kebebasan 100-2-1 = 97 sebesar 1,645 berarti $11,125>1,645$. Maka $\mathrm{H}_{\mathrm{a}}$ diterima dan $\mathrm{H}_{0}$ ditolak, artinya SPM dalam perjalanan $\left(\mathrm{X}_{2}\right)$ mempengaruhi positif serta signifikasi pada loyalitas penumpang (Y). Riset ini sejalan dengan hasil penelitian Wendha, Rahyuda, dan Suasana (2013), kualitas layanan mempengaruhi secara positif serta signifikasi pada kepuasan pelanggan Garuda Indonesia. Semakin baik kualitas layanan maka kepuasan pelanggan bisa meningkat, begitu juga sebaliknya, makin tinggi kepuasan pelanggan, loyalitas akan makin meningkat. Kualitas layanan mempengaruhi secara positif serta signifikasi pada loyalitas pelanggan Garuda Indonesia. Semakin baik kualitas layanan Garuda Indonesia, loyalitas pelanggan meningkat.

Berikut adalah hasil uji-t koefisien regresi variabel SPM dalam perjalanan $\left(\mathrm{X}_{1}\right)$ :

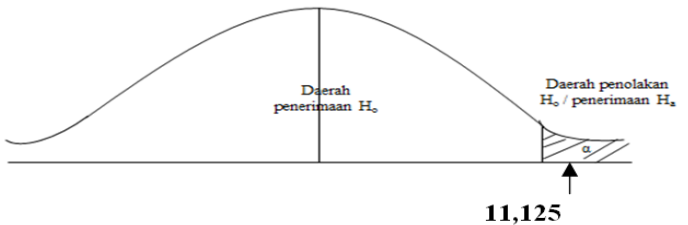

\section{Gambar 4. Hasil Uji-t Koefisien Regresi Variabel SPM Dalam Perjalanan $\left(X_{1}\right)$ \\ Sumber : Data diolah, 2017}

\section{SIMPULAN DAN IMPLIKASI}

1. Tanggapan penumpang mengenai SPM pada stasiun Bogor Paledang dinilai sesuai SPM. Nilai SPM pada stasiun Bogor Paledang tertinggi adalah atribut informasi gangguan perjalanan kereta api dengan interpretasi sesuai yaitu penyampaian informasi gangguan perjalanan kereta api 11-20 menit setelah terjadi gangguan dan nilai SPM di stasiun Bogor Paledang terendah adalah pada atribut informasi fasilitas kesehatan dengan interpretasi mudah terlihat dan terjangkau. Sedangkan tanggapan penumpang mengenai SPM dalam perjalanan disimpulkan nilai ratarata SPM dalam perjalanan memiliki interpretasi sesuai SPM. Nilai SPM dalam perjalanan tertinggi adalah atribut rak bagasi dengan interpretasi sangat mencukupi dan nilai SPM dalam perjalanan terendah adalah pada atribut fasilitas pendukung dengan interpretasi memadai yaitu terdapat 1 unit CCTV setiap gerbong.

2. Secara simultan, SPM pada stasiun $\left(X_{1}\right)$ dan SPM dalam perjalanan $\left(\mathrm{X}_{2}\right)$ mempengaruhi positif signifikasi pada loyalitas penumpang kereta api Pangrango pada stasiun Bogor Paledang. Sedangkan hasil pengujian secara parsial (Uji-t) yaitu SPM pada stasiun $\left(\mathrm{X}_{1}\right)$ mempengaruhi positif signifikasi pada loyalitas penumpang (Y) dan SPM dalam perjalanan $\left(\mathrm{X}_{2}\right)$ mempengaruhi positif signifikasi pada loyalitas penumpang (Y).

Adapun implikasi adalah sebagai berikut: 
1. Pada SPM di stasiun, atribut informasi gangguan perjalanan kereta api dengan interpretasi sesuai yaitu penyampaian informasi gangguan perjalanan kereta api 11-20 menit setelah terjadi gangguan sebaiknya dipertahankan karena sesuai SPM dan untuk atribut informasi dan fasilitas kesehatan dengan interpretasi mudah terlihat dan terjangkau lebih ditingkatkan lagi seperti dengan menyediakan ruang kesehatan khusus untuk penumpang yang membutuhkan tempat istirahat khusus demi memaksimalkan pelayanan agar penumpang merasa puas sehingga menjadi penumpang yang loyal terhadap kereta api. Sedangkan SPM dalam perjalanan pada atribut rak bagasi dengan interpretasi sangat mencukupi tetap dipertahankan dan untuk atribut fasilitas pendukung dengan interpretasi memadai yaitu terdapat 1 unit CCTV setiap gerbong sebaiknya dipertahankan guna meningkatkan pengawasan keamanan di dalam kereta. Dengan kualitas layanan meningkat, maka akan meningkatkan loyalitas penumpang sehingga visi misi perusahaan akan terwujud yaitu menjadikan kereta api sebagai moda transportasi pilihan utama dan terbaik.

2. Bagi yang akan melakukan penelitian pada KA Pangrango hendaknya meneliti variabel lain selain SPM seperti bauran pemasaran dan perilaku konsumen yang berkaitan dengan loyalitas penumpang dan atau kepuasan penumpang serta dapat menjadikan penelitian ini sebagai tambahan data.

\section{UCAPAN TERIMA KASIH}

Ucapan terima kasih kepada PT Kereta Api Indonesia (Persero) yang telah memberikan ijin kepada penulis untuk melakukan penelitian di perusahaannya.

\section{DAFTAR PUSTAKA}

Adnyana, Ketut Ngurah Darma, 2016. Tangible, Reliability, Responsiveness, Assurance, Empathy pada Inovasi Layanan terhadap Kepuasan Wajib Pajak Studi Kasus pada Samsat Corner Tiara Dewata. Jurnal Manajemen dan Bisnis, Denpasar: Undiknas, ISSN 1892-8486, Vol. 13, No. 3, hal. 1-28.

Agung Muhammad Arifin, Dwi Gemina, Endang Silaningsih, 2015. Analisis Tingkat Kepuasan Penumpang pada Fasilitas Bus Transjakarta Berbasis SPM. Jurnal Sosial Humaniora, ISSN 2087-4928, Vol. 6, No. 2, hal. 104-121.

Diona Mahardika K, Veronica dan Supriyono, 2016. Pengaruh Kualitas Pelayanan terhadap Kepuasan Konsumen Jasa Transportasi Kereta Api Indonesia (KAI) Daerah Operasi 6 Yogyakarta. Jurnal Manajemen Pemasaran, ISSN 2337-5221, Vol. 3 No.1, hal. 1-12.

Endang Silaningsih, Dwi Gemina dan Erni Yuningsih, 2015. Transjakarta Company's Strategy and Minimum Service Standard To Raise Passengers Satisfaction. Jurnal Manajemen dan Kewirausahaan, ISSN 1411-1438 print/ ISSN 2338-8234 online, Vol 17, No. 1, hal. 1-10.

Fikri, Sirhan, Wahyu Wiyani, Agung Suwandaru, 2016. Pengaruh Kualitas Pelayanan terhadap Kepuasan dan Loyalitas Mahasiswa. Jurnal Bisnis dan Manajemen, Vol.3, No. 1, Hal. 120-134. Griffin, Ricky W, dan Ronald J.Elbert, 2007, Bisnis, edisi kedelapan jilid satu, Terjemahan, Jakarta: Erlangga.

Nasution, 2015. Manajemen Transportasi, Edisi IV, Ghalia Indonesia: Bogor. 
Pasuraman, A. 2001. Service Quality, Coral Gables, University of Miami, Library Assesment and Benchmarking Institute Moneterey.

Pirbadi, Dessy, 2014. Pengaruh Product Quality, Service Quality, Image terhadap Loyalty Melalui Satisfaction pada Restoran Sunda di Jakarta. Jurnal Manajemen dan Pemasaran Jasa,.7, No.1, hal. 177-198.

PT. KA Pangrango Stasiun Bogor Paledang, 2017. Data Jumlah Penumpang Kereta Api Pangrango Tahun 2016.

Santoso, Septiadi, 2013, Pengaruh Kualitas Pelayanan terhadap Loyalitas Pelanggan Laboratorium Klinik Populer Surabaya. Jurnal Ilmu \& Riset Manajemen, Vol 2, No. 6, hal 1-20.

Semuel, Hatane dan Nadya Wijaya, 2009.

Service Quality, Perceived Value, Satisfaction, Trust dan Loyalty pada PT. Kereta Api Indonesia menurut Penilaian Pelanggan Surabaya. Jurnal Manajemen Pemasaran, Vol 4, No. 1, hal 23-37.

Sugiyono, 2016. Metode Penelitian Kuantitatif, Kualitatif dan R\&D. Bandung. Cetakan Ke-23, Alfabeta.

Tjiptono, Fandy, 2011. Strategi Pemasaran. Yogyakarta.Edisi Pertama, Andi Ofset.

Wendha, A.A Ayu Atika Paramitha, I Ketut Rahyuda, dan I. Gst. A. Kt. G. Suasana, 2013. Pengaruh Kualitas Layanan terhadap Kepuasan dan Loyalitas Pelanggan Garuda Indonesia di Denpasar. Jurnal Manajemen, Strategi Bisnis, dan Kewirausahaan, Vol. 7, No. 1, hal. 19-28. 